\title{
Interstitial Stem Cell Proliferation in Hydra: Evidence for Strain-Specific Regulatory Signals
}

\author{
Charles N. David, ${ }^{*}$ Tosimtaka Fujisawa, $\dagger$ and Tilomas C. G. Bosci ${ }^{*, 1}$ \\ *Zoological Institute, University of Munich, Luisenstrasse 14, 8000 Munich 2. Federal Repnblic of Germany; and $†$ Department of \\ Developmental Genetics. National Institute of Genetics. Yata 1,111, Mishima, Shizuoka 411, Japan
}

Accepted August 16, 1991

\begin{abstract}
We have examined the growth behavior of small numbers of interstitial stem cells transplanted into tissue of genetically unrelated strains of Hydra magnipapillata. We show that such stem cells, which are at low density following transplantation, proliferate more rapidly than the stem eells of the host, which are at normal density. The rapid proliferation is similar to the proliferation rate of stem cells transplanted into interstitial cell free tissue. The results suggest that stem cells transplanted into heterotypic tissue are unable to "sense" the presence of host stem cells and to adopt their growth rate to that of the surrounding cells. Thus, the feedback signal which negatively regulates stem cell growth as a function of stem cell density must be strain specific. 1991 Academic Press, Inc.
\end{abstract}

\section{INTRODUCTION}

Interstitial stems cells in hydra are a rapidly proliferating cell population with a cell cycle of about $24 \mathrm{hr}$ (for review see David et al., 1987). After each cell division cycle about $60 \%$ of stem cell daughters remain stem cells (David and Gierer, 1974). Thus, the stem cell population grows $20 \%$ per day resulting in a doubling time of the interstitial cell population of 3 days. This coincides with the growth rate of the epithelium in which the interstitial stem cells reside and leads to a constant ratio of interstitial cells to epithelial cells during growth of hydra tissue.

Previous results have shown that the stem cell growth rate is negatively regulated by the stem cell density. Regulation of the growth rate occurs by changes in the self-renewal probability $\left(P_{\mathrm{s}}\right)$ (Bode et al., 1976; Sproull and David, 1979; David and MacWilliams, 1978). Reduction of the stem cell density in tissue increases $P_{\mathrm{s}}$ from 0.6 to 0.7-0.8 and causes the stem cell population to double at a rate faster than normal. Conversely, increasing the number of stem cells decreases the self-renewal probability.

The nature of the signal(s) by which interstitial cells measure their density is unknown. Experimental evidence suggests that the feedback signal is of short range since stem cells can detect neighboring cells within a clone but not cells in neighboring clones (David and MacWilliams, 1978; Sproull and David, 1979). Whether the signal is a diffusible molecule produced by stem cells

\footnotetext{
${ }^{1}$ To whom correspondence should be addressed.
}

or whether density measurement is mediated directly by cell-cell contact has not yet been determined.

In experiments which involved grafting of tissue between genetically distinct strains of hydra we discovered that feedback regulation of stem cell growth by stem cell density did not occur. We present here a systematic investigation of this phenomenon and show that stem cells, when mixed with genetically distinct stem cells from different strains of the same species, behave as if these cells were not present. The results suggest that growth regulation of stem cells in hydra involves strain-specific molecules.

\section{MATERIALS AND METHODS}

\section{Strains and Culture Conditions}

Hydra magnipapillata were used for all experiments. The strains were originally isolated by Sugiyama and Fujisawa (1977) from different sites in Japan and have been maintained in laboratory culture since then. The strains are genetically unrelated. Strain 105 is the wild type, strain ms-1 contains stems cells which differentiate immobile sperm, strain sf- 1 has temperature-sensitive interstitial stem cells (animals grown at $18^{\circ} \mathrm{C}$ have stems cells; animals grown at $28^{\circ} \mathrm{C}$ lose their stem cells), and strain reg 16 is regeneration deficient but contains normal interstitial stem cells. Animals were cultured at $18^{\circ} \mathrm{C}$ in a medium containing $1 \mathrm{mM} \mathrm{CaCl}$, $0.1 \mathrm{mM} \mathrm{MgCl}_{2}, 0.1 \mathrm{mM} \mathrm{KCl}$, and $1 \mathrm{mM} \mathrm{NaHCO}$ at $\mathrm{pH}$ 7.8. Animals were fed daily with freshly hatched brine shrimp nauplii. 


\section{Axial Grafting}

Hydra were grafted according to standard procedures by stringing pieces of tissue onto nylon fishline (Fujisawa, 1989). Unless otherwise stated in the text, distal halves of unstained polyps were grafted to proximal halves of polyps which had been vitally stained with Evans blue.

\section{Cell Counting}

Whole animals or excised pieces of tissue were macerated using the standard procedure (David, 1973). The number of large interstitial cells occuring as single cells or in pairs (referred to as $1 \mathrm{~s}+2 \mathrm{~s}$ ) was counted using phase-contrast optics. Interstitial stem cells constitute about half of all 1s $+2 \mathrm{~s}$ (David and Gierer, 1974). When buds were present, they were included in cell determinations.

\section{Labeling of Cells with $\left[{ }^{3} H\right]$ Thymidine and Autoradiography}

Individual animals were labeled by injecting $\left[{ }^{3} \mathrm{H}\right]$ thymidine ( $30 \mathrm{Ci} / \mathrm{mmol}$; Amersham, England) into the gastric cavity; $0.1 \mu \mathrm{l}$ of a solution containing $1 \mathrm{mCi} / \mathrm{ml}$ was injected per animal. For autoradiography dried slides with macerated cells were dipped in Kodak NTB-2 emulsion, exposed for 10 days at $4^{\circ} \mathrm{C}$, and developed.

\section{Immunocytochemistry}

Interstitial cells were visualized in whole mounts using an specific monoclonal antibody (C41) isolated by 'Tobias Schmidt. Polyps were fixed for at least $1 \mathrm{hr}$ in Lavdowsky's fixative, washed several times in PBS, and incubated in C41 hybridoma supernatant overnight. After several washes in PBS they were incubated with FITC-conjugated goat anti-mouse Ig (Amersham, diluted 1:50 in PBS:BSA) for $2 \mathrm{hr}$, rinsed in PBS, mounted, and examined on a Leitz Dialux 20 microscope with an epifluorescence attachment.

\section{RESULTS}

\section{Growth of Interstitial Stem Cells Transplanted into Genetically Unrelated Host Tissue.}

Interstitial stem cells of $H$. magnipapillata strain 105 were introduced into $H$. magnipapillata strain sf -1 by axial grafting. Distal and proximal halves were grafted together for 2 days as shown schematically in Fig. 1. During the 2-day period of parabiosis, small numbers of interstitial cells migrate from the proximal to the distal half (Fujisawa et al., 1990). Some of these cells are stem cells which continue to proliferate in the distal half. After 2 days of parabiosis the distal halves were isolated

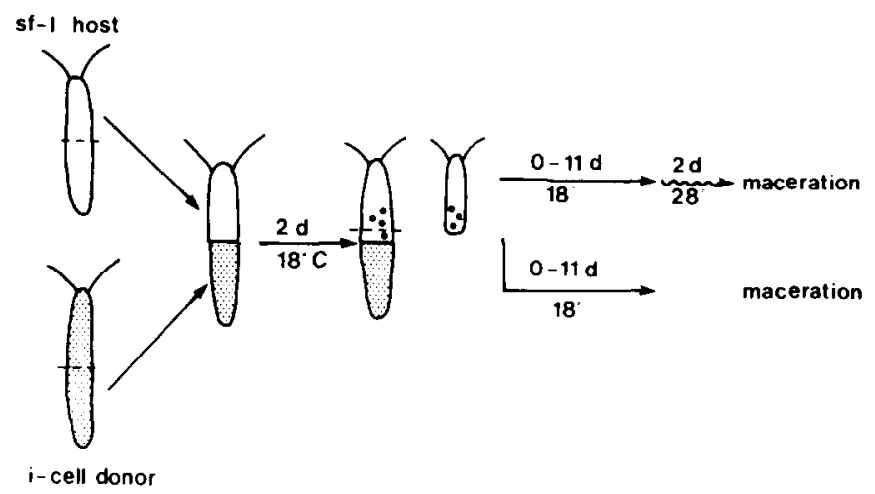

FIG. 1. Schematic representation of transplantation procedure used to produce heterotypic axial grafts. Donor polyps were vitally stained with Evans blue.

and incubated for an additional 711 days at $18^{\circ} \mathrm{C}$ to permit further growth of the donor stem cell population. To distinguish donor from host stem cells, interstitial cells of the sf- 1 host were then eliminated by a temperature shift to $28^{\circ} \mathrm{C}$ for 2 days. The numbers of donor interstitial cells were determined by maceration.

Figure 2 shows that during the first 6 days after isolation the donor stem cells proliferated rapidly and exponentially with a doubling time of about 1 day which is much faster than the doubling time of the surrounding epithelium. Since the proliferation of interstitial stem cells in hydra tissue is tightly correlated with that of the epithelial cells (e.g., data for total interstitial cells in Fig. 2), the rapid growth of donor 105 cells in sf- 1 tissue appears to be the result of grafting into a genetically distinct strain.

Figure 2 also shows that the doubling time of transplanted interstitial cells slowed to about 4 days in longterm grafts and thus coincided with the doubling time of the epithelial cell population. At this point the number of grafted cells had increased considerably. Thus, normal growth rates are correlated with high numbers of transplanted cells. Rapid growth, by comparison, apparently only occurs at low cell numbers.

Independent observations have demonstrated that donor stem cells grow rapidly with a doubling time of 1-2 days in host tissue lacking interstitial cells due to nitrogen mustard treatment (see Fig. 5 in Bosch et al. 1991). Thus, donor cells grow in the absence of interstitial cells with essentially equal rapidity as when in the presence of heterotypic interstitial cells. This suggests that the density-dependent regulation of stem cell growth, which is mediated by the presence of homotypic interstitial cells, can not be mediated by heterotypic interstitial cells.

\section{Localization of Heterotypic Stem Cells in sf-1 Tissue}

In order to localize the rapidly proliferating donor stem cells in heterotypic grafts we used the procedure 


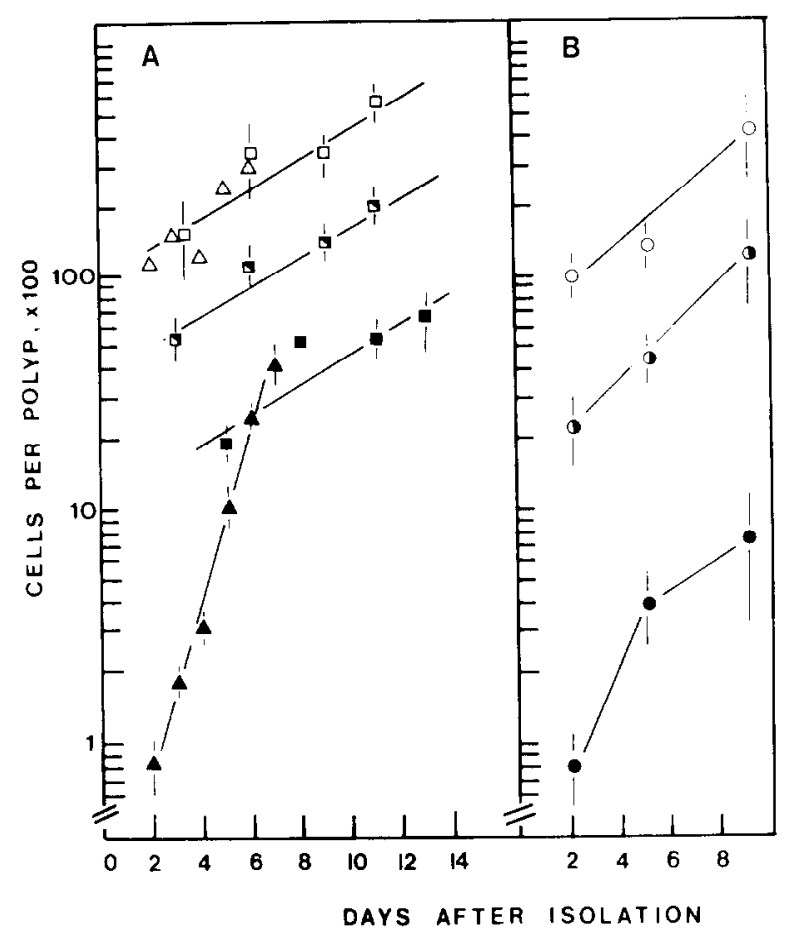

FIG. 2. Growth of epithelial and interstitial cells in heterotypic s[-1/ 105 grafts. Results of three independent experiments are indicated by different symbols. Distal isolates contain fewer cells in B than A since isolation of the top halves in $\mathrm{B}$ was done well above the graft border. Values with error bars are means $( \pm \mathrm{SD})$ of $3-5$ independent determinations; $5-10$ isolates were pooled per determination. Ordinate: cells per polyp include cells from both the parent polyp and any buds produced during the experiment. Open symbols, epithelial cells; half-open symbols, total interstitial cells; closed symbols, donor interstitial cells.

outlined in Fig. 1. Donor interstitial cells were visualized 2 and 7 days after isolation using an interstitial cell-specific monoclonal antibody (for details see Material and Methods). Figure 3A shows that 2 days after isolation, temperature-resistant donor interstitial cells were found within a single patch in the lower part of the host tissue near the original graft junction. Cultivation for longer periods of time did not lead to extensive migration of donor cells within the host tissue. Figurc 3B shows that 7 days after isolation, donor interstitial cells continued to be localized in a contiguous patch in the lower part of the host animal; part of the patch was incorporated into evaginating buds. Since donor interstitial cells were only found in a region of the host tissue very close to the former grafting border, it appears that heterotypic stem cells do not infiltrate host tissue extensively.

\section{Rapid Grouth of Donor Cells in Heterotypic Grafts}

Depends on Interstitial Cells and Not Epithelial Cells

The results in Fig. 2 suggest that rapid growth of 105 interstitial cells in sf- 1 tissue is due to incompatibility in the mechanism of density-dependent growth control. Grafted 105 cells appear unable to detect the resident interstitial cells and hence proliferate rapidly as if they were at low density. To demonstrate directly that rapid growth depends on the genotype of the host interstitial cells and not of the epithelial cells, 105 cells were grafted to a chimeric strain consisting of 105 epithelial cells and sf-1 interstitial cells (Sugiyama and Fujisawa, 1978; Marcum and Campbell, 1978) using the procedure shown in Fig 1. In this chimeric tissue 105 interstitial cells grew rapidly with a doubling time of 1.4 days while the host epithelial cells doubled in 4.2 days. Since changing the epithelial cells does not affect the growth behavior of interstitial cells, we conclude that rapid growth is due to incompatibility between donor and host interstitial cells.

Control grafts shown below (Fig. 4) demonstrate that rapid growth of donor interstitial cells is not due to the grafting procedure itself. In homotypic grafts in which labeled 105 interstitial cells were grafted into 105 animals or labeled sf- 1 cells into sf- 1 animals, interstitial cells always grow with doubling time of about 3-4 days which is similar to the growth rate of the epithelial cells (Takano et al., 1980).

\section{Evidence for Strain-Specific Growth Regulation in Further Heterotypic Strain Combinations}

To determine whether the rapid growth of grafted interstitial cells was an unusual property of strains sf-1 and 105 or a general feature observable in hydra, we tested combinations of several other strains of $\mathrm{H}$. magnipapillata using the procedure shown in Fig. 4A. In these experiments donor cells were pulse-labeled with $\left[{ }^{3} \mathrm{H}\right]$ thymidine prior to grafting in order to distinguish them from host cells. Proliferation of donor cells was followed for 3 days during which time the nuclear label of donor cells was clearly distinguishable despite continuing cell division. The results in Figs. $4 \mathrm{~B}$ and $4 \mathrm{C}$ indicate that donor interstitial stem cells grow slowly in all homotypic grafts (Fig. 4B) with a doubling time of about $2-3$ days but rapidly in all heterotypic grafts (Fig. 4C) with a doubling time of about 1 day in all strains tested.

\section{Increased Number of Total Interstitial Cells in Heterotypic Grafts}

The results above (Figs. 2 and 4 ) suggest that donor cells grow rapidly in heterotypic host tissue because they do not detect the resident host interstitial cells. Thus, one would expect to find with time an increase in the total number of interstitial cells in host tissue. To look for such an increase we prepared axial grafts as shown in Fig. 5A. In these one-quarter/three-quarter grafts the host tissue is reduced in size so that migrated 


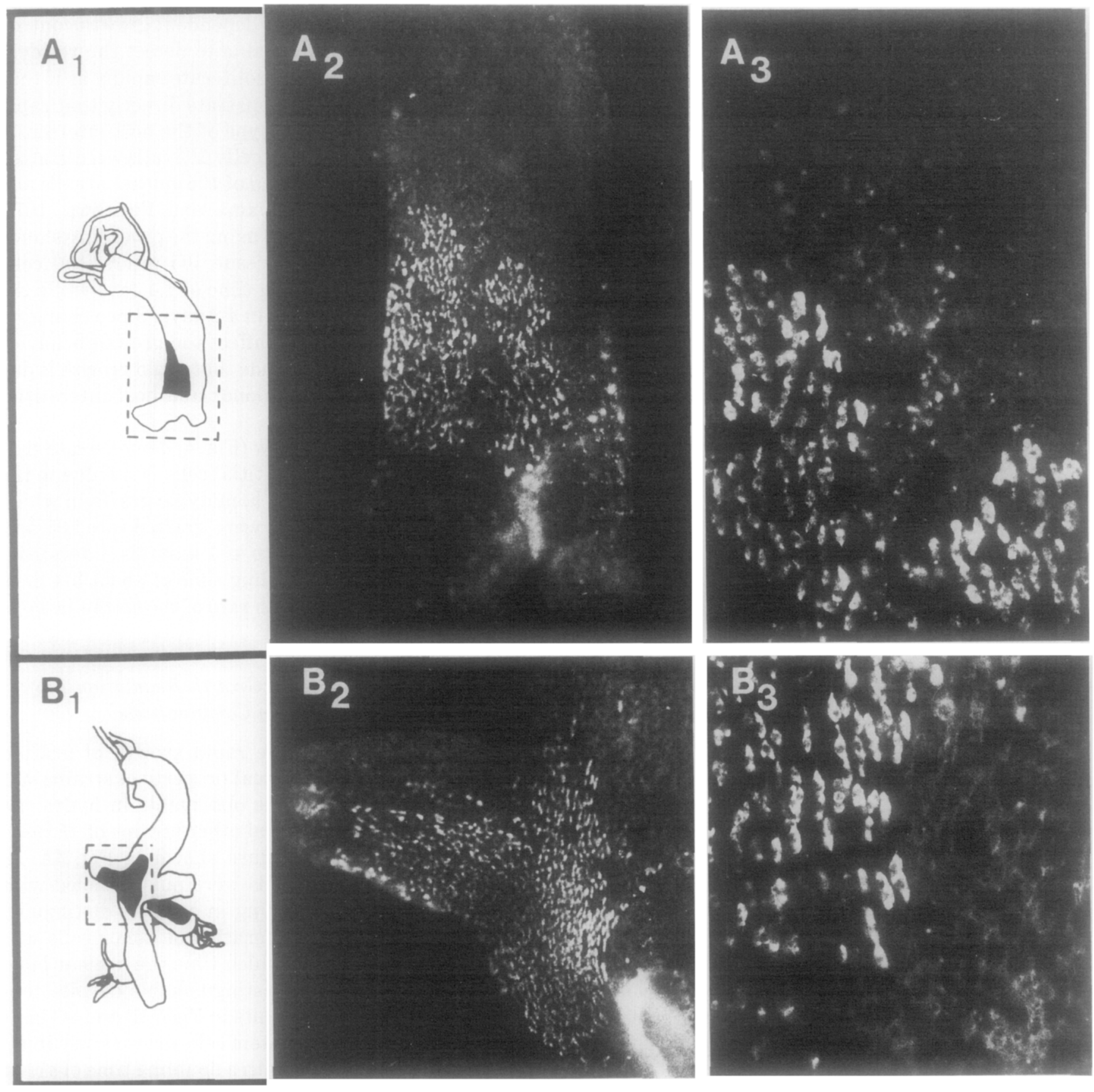

Fig. 3. Immunolocalization of 105 interstitial cells in sf-1 tissue. Interstitial cells were stained with monoclonal antibody C41 and visualized with indirect immunofluorescence. (A) Host tissue 2 days after graft separation. (B) Host tissue 5 days after graft separation. $\left(A_{1}\right.$, $\left.B_{1}\right)$ Camera lucida drawing of whole mount showing localization of the interstitial cell clone and orientation of the photograph. $\left(A_{2}\right.$ and $\left.B_{2}\right)$ Magnification $\times 50 .\left(A_{3}\right.$ and $\left.B_{3}\right)$ Magnification $\times 100$.

interstitial donor cell numbers approach resident host cells number more rapidly. The grafts were kept together for 2 days at $18^{\circ} \mathrm{C}$. Thereafter the host tissue was isolated and incubated for up to 7 days at $18^{\circ} \mathrm{C}$. Since the tissue was not temperature treated, the total interstitial cell population (donor and host interstitial cells) was scored. The results in Fig. 6 show that the density of interstitial cells in heterotypic grafts (Fig. 6A) increased markedly from $0.101 \mathrm{~s}+2 \mathrm{~s} /$ epithelial cell at Day 0 to $0.291 \mathrm{~s}+2 \mathrm{~s} /$ epithelial cell at Day 9 after graft separation. In homotypic control grafts (Fig. $6 \mathrm{~B}$ ) only a slight increase in density from $0.101 \mathrm{~s}+2 \mathrm{~s} /$ epithelial 


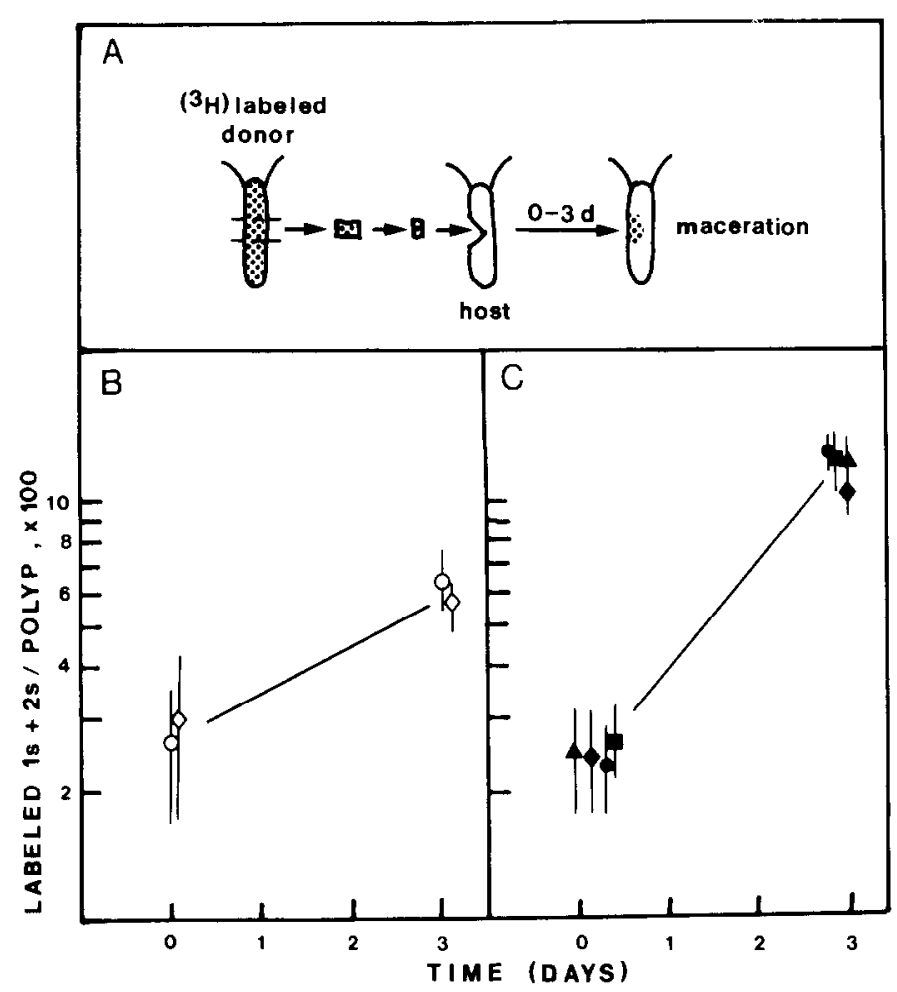

FIG. 4. Growth rate of interstitial cells in homotypic (B) and heterotypic (C) tissue. (A) Schematic representation of transplantation procedure used. Values shown are means $( \pm \mathrm{SD})$ of two to three independent determinations; 5-10 polyps were pooled per determination. Open circles, 105/105; open diamond, sf $1 /$ sf 1 . Closed triangle, 105/sf1; closed diamond, sf $1 / 105$; closed circle, reg 16/sf1; closed squares, reg $16 / 105$.

cell to $0.141 \mathrm{~s}+2 \mathrm{~s} /$ epithelial cells was observed which most likely is due to the regeneration of the upper onequarter pieces to normal polyps.

An increase in interstitial cell density was also observed in heterotypic tandem grafts which consisted of alternating rings of strains 105 and sf -1 (Fig. 5B). The interstitial cell density in such grafts was analyzed 2 and 5 days after grafting. The results in Table 1 indicate that there was a significant increase in the density of interstitial cells in heterotypic combinations compared to homotypic grafts consisting of rings of 105 tissue only.

\section{DISCUSSION}

\section{Strain-Specific Regulation of Interstitial Cell Growth}

Previous results have shown that stem cell proliferation in hydra is negatively regulated by the density of stem cells in the tissue (Bode et al., 1976; Sproull and David, 1979). Growth regulation occurs via changes in the fraction of daughter cells which remain stem cells in each stem cell generation. Under normal conditions stem cells are present at a density of about 0.3 stem cells/epithelial cells; $60 \%$ of daughter cells remain stem cells per generation $\left(P_{\mathrm{s}}=0.6\right)$. Decreasing the number of stem cells causes an increase in $P_{\mathrm{s}}$ to $0.7-0.8$ which doubles the growth rate of the stem cell population and leads to recovery of normal stem cell levels in tissue.

The experiments reported here show that low numbers of donor stem cells from strain 105 grow in strain sf -1 hosts at a rapid rate, while stem cells of the host, which are present at a high density, grow at a slower rate (Fig. 2). Thus the donor cells appear to be unable to detect the presence of interstitial cells of the host strain. We conclude, therefore, that the feedback signal by which donor 105 cells detect the presence of neighboring stem cells is not functional when the neighbors are from strain sf-1. Thus the negative feedback signal which measures stem cell density is strain specific.

This conclusion is not limited to strains sf- 1 as host or strain 105 as donor since rapid growth of donor stem cells was also observed in several other heterotypic combinations (Figs. $4 \mathrm{C}$ and $6 \mathrm{~A}$ ). The rapid proliferation of donor cells is also not a result of the grafting procedure itself since homotypic grafts between donor and host tissue of the same strain did not stimulate proliferation of the donor interstitial stem cells (Figs. $4 \mathrm{~B}$ and $6 \mathrm{~B}$ ). Figure 7 directly compares the growth rates of donor stem cells in all the heterotypic and homotypic combinations reported in this investigation.

Our results demonstrate that donor interstitial stem cells do not detect the presence of the host stem cell population in heterotypic grafts. Since only peptides would appear to have the necessary genetic complexity to mediate such a strain-specific signature, it seems likely to us that the feedback signal is a peptide/protein. The signal might well be a membrane protein whose action is mediated by direct cell-cell contact between stem cells since the feedback signal has been shown to have a short range (David and MacWilliams, 1978; Sproull and David, 1979). If cell-cell contact is indeed involved in transmission of information about stem cell density, it might be mediated by a mechanism similar to that which in insects controls the decision of neuroectodermal cells to differentiate to nerve cells and epidermal cells (for review see Campos-Ortega, 1990). In this case the signal is mediated by several genes whose products are known to be transmembrane proteins. We show elsewhere (Bosch et al., 1991) that the growth rate of interstitial cells is influenced not only by the density of interstitial cells but also by the nerve cell density. In contrast to the short range and strain-specific feedback signal which mediates information about the stem cell density, the influence of nerve cells on the growth rate 

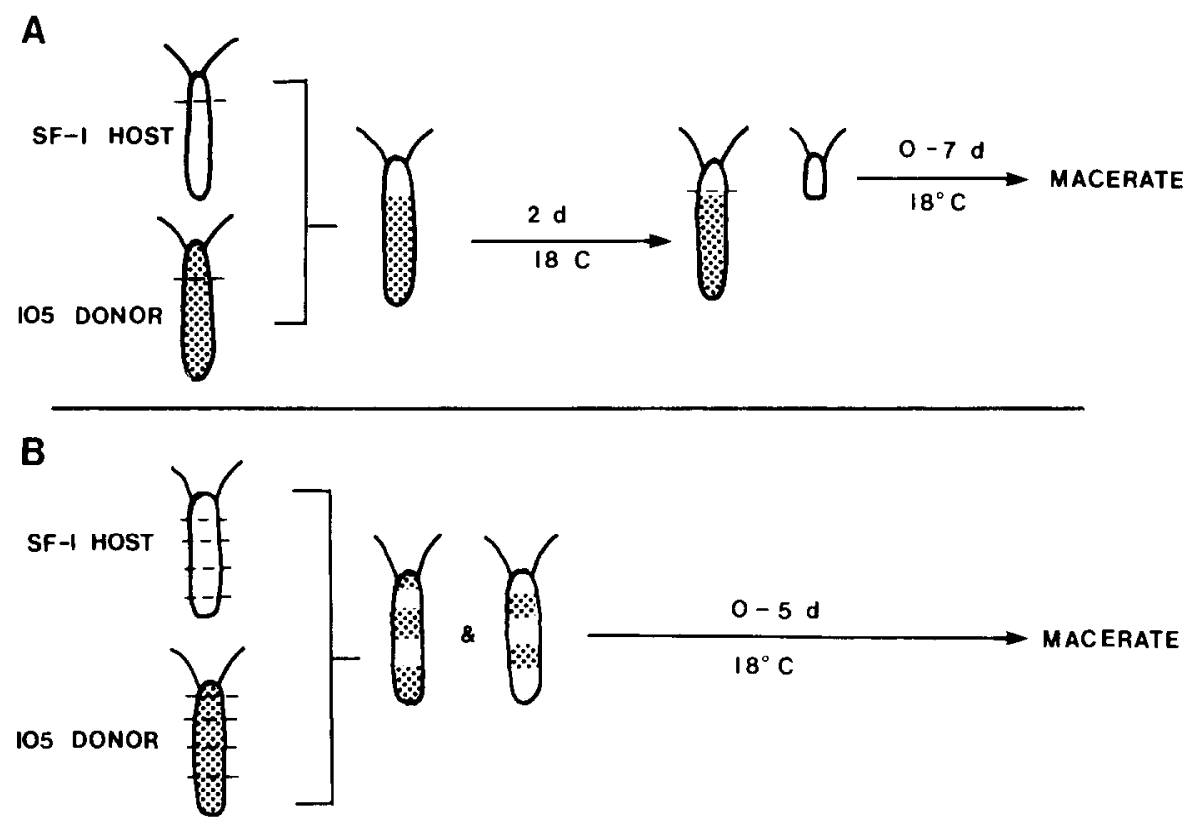

FIG. 5. Transplantation procedure used to analyze growth of interstitial cells in heterotypic grafts tissue. Donor polyps were vitally stained with Evans blue. (A) One-quarter/three-quarter grafts; (B) Tandem grafts. Note that all interstitial cells (from donor and host) were analyzed.

of interstitial cells is of long range and not strain specific.

\section{Role of Historecognition in Hydroid Biology}

In grafts between two different species of hydra $(H$. oligactis and $H$. vulgaris) we have previously shown that both epithelial cells and interstitial cells of one species can be recognized by epithelial cells of the other species

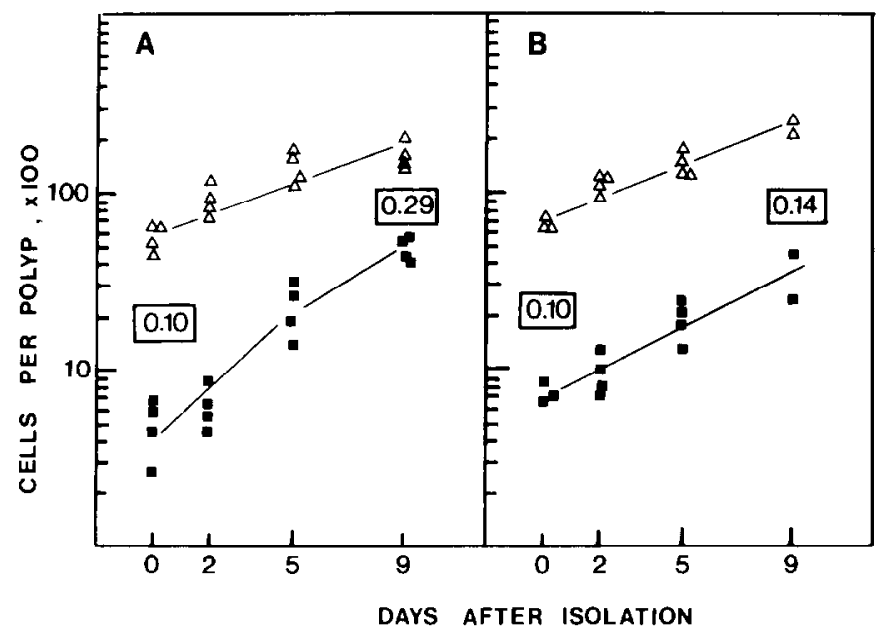

FIG. 6. Growth of epithelial cells and interstitial cells in heterotypic (A) and homotypic (B) one-quarter/three-quarter grafts. Symbols represent independent determinations; 5 - 10 grafts were pooled per determination. Open triangles, epithelial cells; closed squares interstitial cells. Value in inlet represent mean density of interstitial cells $(1 \mathrm{~s}+$ 2s/epi) at Days 0 and 9.
(Bosch and David, 1986). The observation of strain-specific stem cell growth, however, was surprising since there have been no previous reports of strain-specific phenomena in Hydra. By comparison, in colonial marine hydroids such as Hydractinia the genetic individuality of colonies has been clearly documented (Hauenschild, 1954, 1956; Buss et al., 1984). Individual colonies recognize each other. Stolons from the same colony fuse; stolons of different colonies do not fuse. Contact between nonfusing colonies leads to a dramatic rejection reaction. Buss (1982) has proposed that this rejection reaction evolved in colonial organisms, which grow by ramet formation and hence contain a proliferating germline, to prevent parasilic takeover by germline cells of another colony (the somatic cell parasitism hypothesis). Assuming that growth regulation of stem cells in $\mathrm{Hy}$ -

TABLE 1

INCREASE IN INTERSTITIAL CELL DENSITY IN HeTERoTyPIC TANDEM GRAFTs ${ }^{a}$

\begin{tabular}{cccc}
\hline & \multicolumn{3}{c}{$1 \mathrm{~s}+2 \mathrm{~s} /$ Epithelial cell } \\
\cline { 2 - 4 } $\begin{array}{c}\text { Days after } \\
\text { grafting }\end{array}$ & $105 / 105$ & $\mathrm{sf} 1 / \mathrm{sf} 1$ & $105 / \mathrm{sf}-1$ \\
\hline 0 & $0.215(0.02)$ & $0.172(0.03)$ & $0.185(0.007)$ \\
2 & $0.215(0.007)$ & N.D. & $0.328(0.036)$ \\
5 & $0.206(0.019)$ & N.D. & $0.301(0.008)$ \\
\hline
\end{tabular}

${ }^{a}$ Grafts were produced as shown in Fig. 5B. Data represent mean values ( $\perp$ standard deviation) of two independent experiments. Five or six grafts were pooled per determination. 


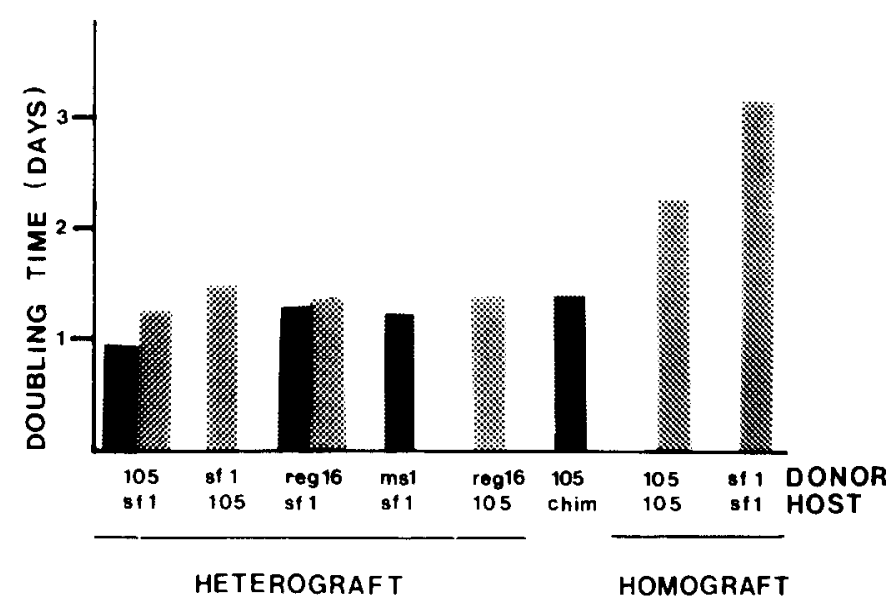

FIG. 7. Doubling time (days) of donor interstitial cells in heterotypic and homotypic tissue. The doubling time was estimated from the growth rates of interstitial cells shown in Figs. 2 and 4. Doubling time of donor cells in sf-1 epithelial/105 interstitial cell chimeric tissue (chim) is given in text. Crey bars, doubling time of $\left[{ }^{3} \mathrm{H}\right]$ thymidinelabeled interstitial cells in unlabeled host tissue; black bars, doubling time of interstitial cells in temperature treated host tissue.

dractinia occurs by a mechanism similar to that of $\mathrm{Hy}$ $d r a$, then the need for a self/non-self recognition system is clearly demonstrated by our experiments. Were stem cells of one colony to invade a second colony as a result of stolon fusion, they would have a clear growth advantaos and could in nrincinle reduce the contribution of host stem cells to gamete formation.

We thank N. Sugimoto for technical assistance and Dr. T. Sugiyama for critically reading the manuscript. This work was supported by a Grant-in-Aid for Scientific Research from the Ministry of Education, Science and Culture in Japan and by the Deutsche Forschungsgemeinsehaft (Da 163/1-3 and SFB 190). Part of the work was done while T.C.G.B. was in the laboratory of Dr. T. Sugiyama in Mishima, Japan. T.C.G.B. thanks the Deutsche Forschungsgemeinschaft for support (Bo 848/2-1) and Dr. T. Sugiyama for generous hospitality.

\section{REFERENCES}

BoDE, H. R., FLICK, K. M., and SMITH, G. S. (1976). Regulation of interstitial cell differentiation in Hydra attenuata. I. Homeostatic control of interstitial cell population size. J. Cell Sci. 20, 29-46.

Bosch, 'T. C. G., and DAvid, C. N. (1986). Immunocompetence in $\mathrm{Hy}$ dra: Epithelial cells recognize self-nonself and react against it. $J$. Exp. Zool. 238, 225-234.

Bosch, T. C. G., and David, C. N. (1987). Stem cells of Hydra magnipa- pillata can differentiate into somatic cells and germ line cells. Dev. Biol. 121, 182-191.

Bosch, T. C. G., Rollbühler, R., Scheider, B. and C. N. DAvid (1991). Role of the cellular environment in interstitial stem cell proliferation in hydra. Wilhelm Roux Arch. Dev. Biol., in press.

Buss, L. W. (1982). Somatic cell parasitism and the evolution of somatic tissue compatibility. Proc. Natl. Acad. Sci. USA 79, 5337-5341.

Buss, L. W., MCH'ADDEN, C. S., and KEENE, D. R. (1984). Biology of hydractiniid hydroids. 2. Histocompatibility effector system/competitive mechanism mediated by nematocyt discharge. Biol. Bull. 167, 139-158.

CAmpos-Ortega, J. A. (1990). Mechanisms of a cellular decision during embryoinic development of Drosophila melanogaster: Epidermogenesis and neurogenesis. Adv, Genet. 27, 403-453.

DAvID, C. N. (1973). A quantitative method for maceration of $I I y d r a$. tissue. Wilhelm Roux Archiv. Entwicklungsmech. Org. 171, 259-268.

David, C. N., Bosch, T. C. G., Hobmeyer, B., Holstein, T., and SchmidT, T. (1987). Interstitial stem cells in hydra. In "Genetic Regulation of Development” (W. F. Loomis, Ed.), pp. 389-408. Liss, New York.

David, C. N., and Gierer, A. (1974). Cell cycle kinetics and development of Hydra attenuata. III. Nerve and nematocyte differentiation. J. Cell Sci. 16, 359-375.

DAvid, C. N., and MACWilliams, H. K. (1978). Regulation of the selfrenewal probability in hydra stem cell clones. Proc. Natl. Acad. Sci. USA 75, 886-890

FUJISAWA, T. (1989). Role of interstitial cell migration in generation position-dependent patterns of nerve cell differentiation in $H y d r a$. Den. Biol. 133, 77-82.

Fujisawa, T., David, C. N., and Bosch, T. C. G. (1990). Transplantation stimulates interstitial cell migration in hydra. Den. Biol. 138, 509-512.

Hauenschild, C. (1954). Genetische und entwicklungsphysiologische

bei Hydractinia echinata. Wilhelm Roux'Archiv, Dev. Biol. 147, 1-41.

HAUENSCHILD, C. (1956). Über die Vererbung einer Gewebeverträglichkeit bei dem Hydroid-Polypen Hydractinia echinata. Z. $\mathrm{Na}$ turforsch. 11, 132-138.

MARCUM, B. A., and CAMPBELL (1978). Development roles of epithelial and interstitial cell lineages in hydra: Analysis of chimeras. J. Cell Sci. 32, 233-247.

Sproull, F., and David, C. N. (1979). Stem cell growth and differentiation in Hydra attenuata. I. Regulation of the self-renewal probability in multiclone aggregates. J. Cell Sci. 38, 155-169.

Sugryama, T., and Funisawa, T. (1977). Genetic analysis of developmental mechanisms in hydra. I. Sexual reproduction of Hydra magnipapillata and isolation of mutants. Dev. Growth Differ. 19, 187 200.

Sugryama, T., and Fujisawa, T. (1978). Genetic analysis of developmental mechanisms in hydra. II. Isolation and characterization of an interstitial cell deficient strain. J. Cell Sci. 29, 35-52.

Takano, J., FujISAwa, T., and SugiYama, T. (1980). Growth rate and cell cycle of hydra. In "Development and Cellular Biology of Coelenterates" (P. Tardent, Ed.), pp. 409 414. Elsevier/North Holland Biomedical Press. 